\title{
Rural To Urban Migration in an Indian Metropolis: Case Study Chennai City
}

\author{
${ }^{1}$ K.Vinayakam, ${ }^{2}$ S.P.Sekar \\ ${ }^{1}$ Research Scholar, Department Of Planning, Sap, Anna University, Chennai. \\ ${ }^{2}$ Professor, Department of Planning, SAP, Anna University, Chennai
}

\begin{abstract}
Chennai city is the forth largest metropolis. It has a population of 46.81 lakh by 2011 census, it is expected to grow more by 50.08 lakh in 2012. Considerable proportion of migrated population particularly in large and metropolitan cities lives in marginal settlements, slums and squatter areas with limited infrastructure services threatening health, environmental degradation of urban areas, traffic and other problems of urban areas. The study describes the factors contributing towards rural to urban migration. In rural areas, less employment opportunities, low wages, drought, lack of basic amenities, landlessness, social factors act as push factors and more employment opportunities, higher income, better wages, better facilities activities as pull factors towards the rural to urban migration
\end{abstract}

\section{Introduction}

In India the urban population is 37.7 million in the year of 2011 (as per census) i.e. the 31.16 percent of the total population. The total population in the year of 2011 was 83.3 million in rural areas and 37.7 million in urban population. This urban population of 37.7 million is very close to the American total population. The percent decadal growth of the population in rural and urban areas in the decade ending of the year 2011 was 12.2 and 31.8 percent

Tamilnadu is one of the 28 states in India and $11^{\text {th }}$ largest state in India by area. It is the $2^{\text {nd }}$ largest state economy in India as of 2012. Tamilnadu is also the most urbanized area state in India. The total poplation is 7.21 million as per 2011 census in this the urban population is 3.49 million and rural population is 3.71 million. Tamilnadu population represents about $5.96 \%$ of the population of India. More people in Tamilnadu have moved from rural to urban areas in the last 10 years compared to other states, according to the 2011 census data. Tamilnadu tops the list of urbanized state with $48.45 \%$ of its population living in Urban areas.

Chennai city is the $4^{\text {th }}$ largest city in India and having $2^{\text {nd }}$ largest beach in the world. Chennai district is a district in the State of Tamilnadu out of 32 districts. It is the smallest of the entire district in the state, but has the highest human density. The most significant phenomenon in Chennai city is massive urbanization. Chennai city Metropolitan Area covers 174 sq.kms. The population of Chennai city which was 14.16 lakh in 1951, increased 24.69 lakh in 1971, and further it was 38.41 lakh in 1991. Now in 2011 the population of the Chennai city was 46.81 as per the census of India.

Chennai city having 10 corporation zones with 155 wards in 2010, from this 10 corporation zones, (now it is 200 wards with 15 zones) it is difficult to find out the migrated people in all the areas, hence a random sampling was adopted in the areas and conduct interview to conduct socio-economic surveys to collect the information of the migrants. The field work was collected during April 2009 to April 2010.

The main objective of this paper is to study the various reasons of immigration for rural areas to urban area especially Chennai city.

\section{Methodology Of The Study}

This study this been carried out with the help of collection of the primary and secondary data. The primary survey is mainly of the observations and interviews through the questionnaire methods. In this questionnaire that there are 32 questions about the year of migration, age of the respondent, gender of the respondent, educational qualification, current job, area of specialization monthly income, native place of the respondent, the living and working condition, reason for migration, motivation for migration, distance of the migration with other related questions of the migrants. These questions were asked from 305 migrated peoples in the 10 zones of the Chennai City Corporation areas under random sampling method.

\section{The Result And Discussions}

The first details were collected as the native district of the migrants within Tamilnadu and next second one is other than Tamilnadu. The third one is the distance from the native place. The fourth one is the motivation to move to Chennai city. The fifth one is the reason for migration from native place to Chennai city 
and the sixth one is the present living area zones in Chennai city. These five details are analyzed as follows as per the data collected from 305 respondent of migrated people.

\subsection{The Native District Of The Migrants Within Tamilnadu}

From the Figure -1 show that the native district in Tamilnadu of the migrants are from Salem $8 \%$, Trichry 7\%, Cuddalore 6\%, Kanyakumari 6\%, Madurai 6\% are showing the high range of the migrants moved to Chennai and other districts are showing lesser range of the migrants moved to Chennai district. Ariyalur and Pudukkottai Districts are showing very lesser range of the migrants respectively $1 \%$ moved to Chennai district out of the 305 respondents.

\section{FIGURE -1: NATIVE DISTRICT OF MIGRANTS WITHIN TAMILNADU}

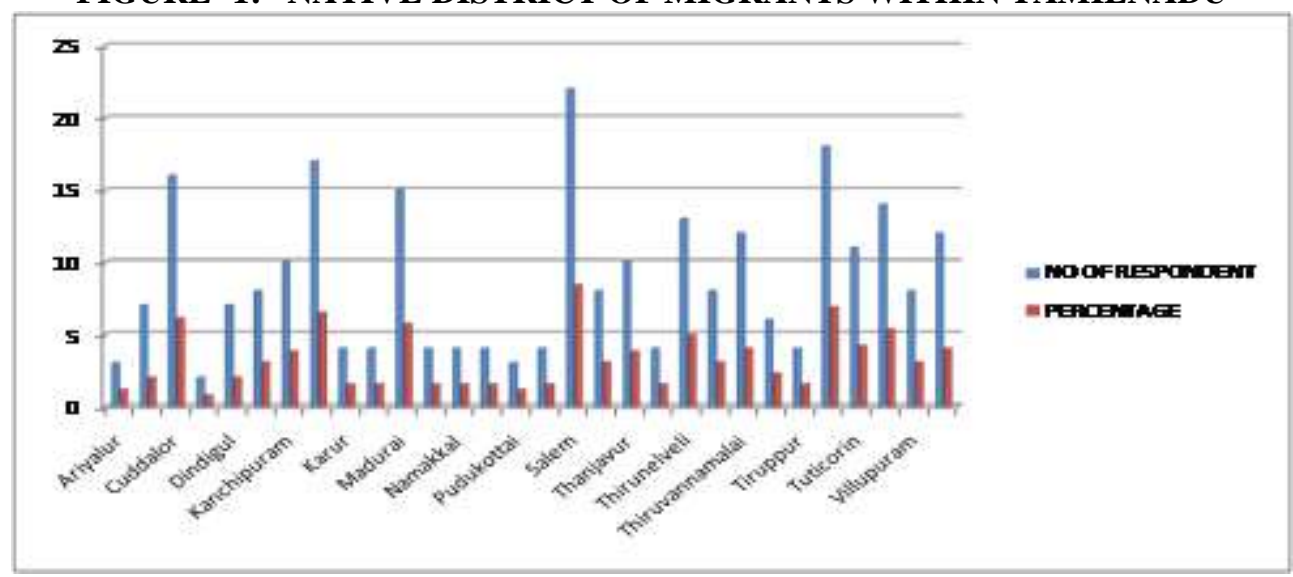

\subsection{The Native State Of The Migrants Other Than Tamilnadu}

From the Figure - 2 shows that the migration range from other than Tamilnadu states are more from Andhra Pradesh 6\% and from Kerala 4\% and all other neighboring states people moved to Chennai city is less this has been calculated according to the 305 migrant respondents.

Figure-2: Native State Of The Migrants Other Than Tamilnadu

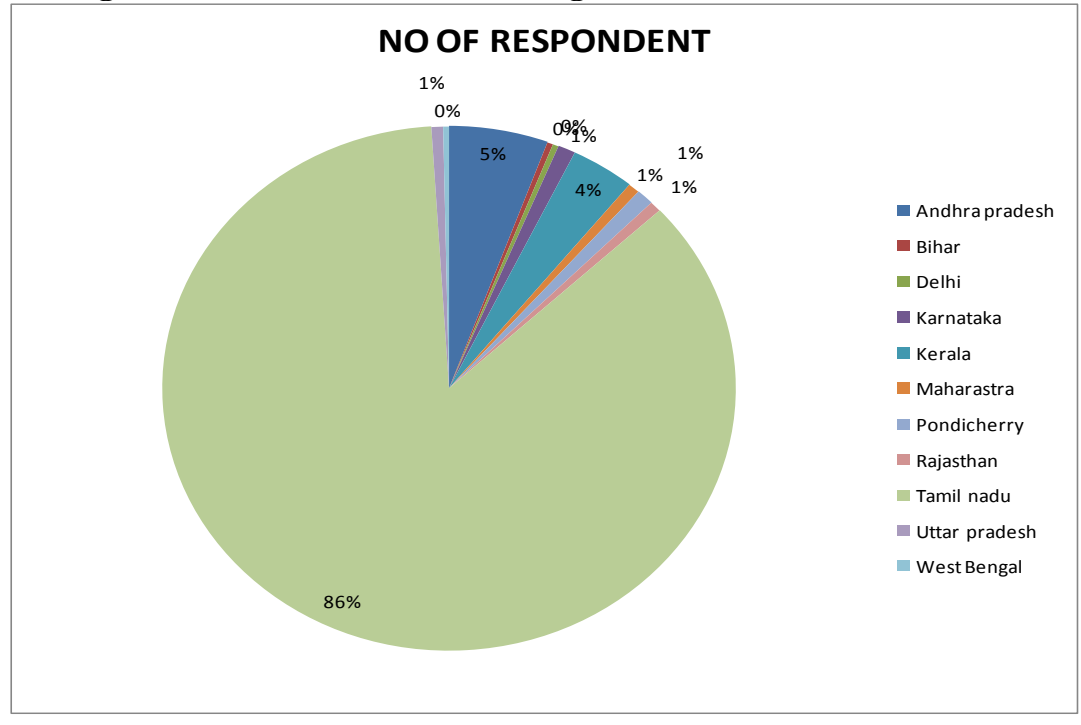

\subsection{The Distance Which The Migrants Came From}

From the Figure - 3 shows that the range of the distance of migrants from their natives place from 151-300 kms.is $22 \%$ and from $301 \mathrm{kms}$. is $36 \%$ and all other ranges of 0-150 kms, 451-600 kms, 601-750 kms, 751-900 kms. and $901 \mathrm{kms}$ and above are mostly Less than $13 \%$. Hence, people who are migrated from their native place distance are ranging from $151 \mathrm{kms}$ to $450 \mathrm{kms}$. are more from the servey of 305 migrant respondents. 
Figure - 3: The Distance Which The Migrants Came From

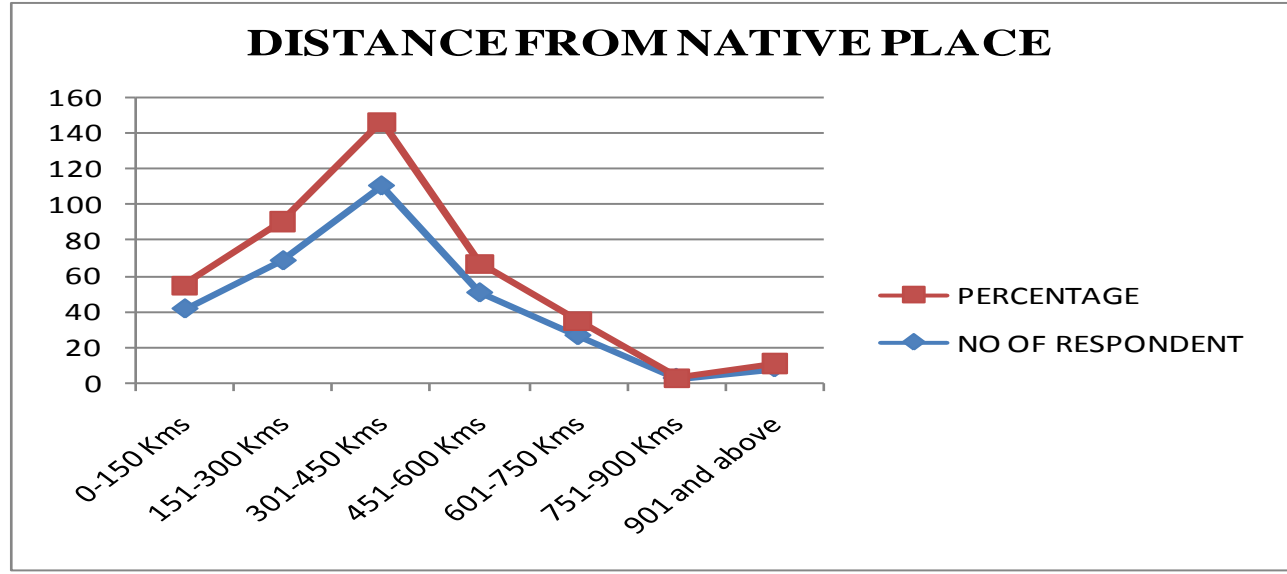

\subsection{The Motivation Which The Migrants To Move To Chennai City}

From the Figure - 4 shows that the motivation for migration ranges of migrants are mostly higher through interviews $40 \%$ and through relatives $33 \%$. The other motivations to move to Chennai are through friends, by employer and other motivations are less than $11 \%$. Hence, the main motivation is interview for job purpose and through relatives for job, business and marriage purposes. The other motivation purposes of friends, by employer and others are very lesser percentage out of the 305 migrant respondents.

Figure - 4:Motivation Of The Migrants To Move To Chennai City

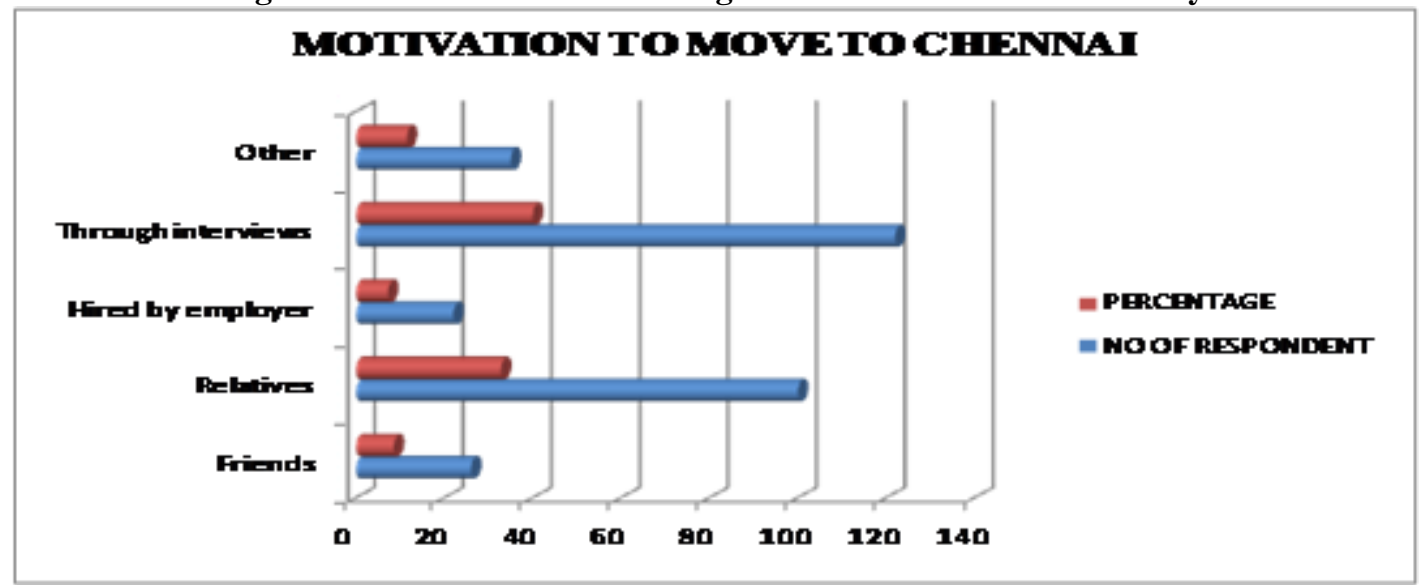

\subsection{The Main Reason For Migration From Rural To Chennai City}

From the Figure - 5 shows that the reason for migration are mostly for Job 74\%, for Business $10 \%$ and for Marriage 6\%. All other reasons for migration of Education, Employment, Family problem, Parent transfer, Individual transfer are less than $5 \%$ this is out of 305 respondents of migrated people. Hence, the main purpose of migration is job.

Figure - 5 Reason For Migration From Rural To Chennai City

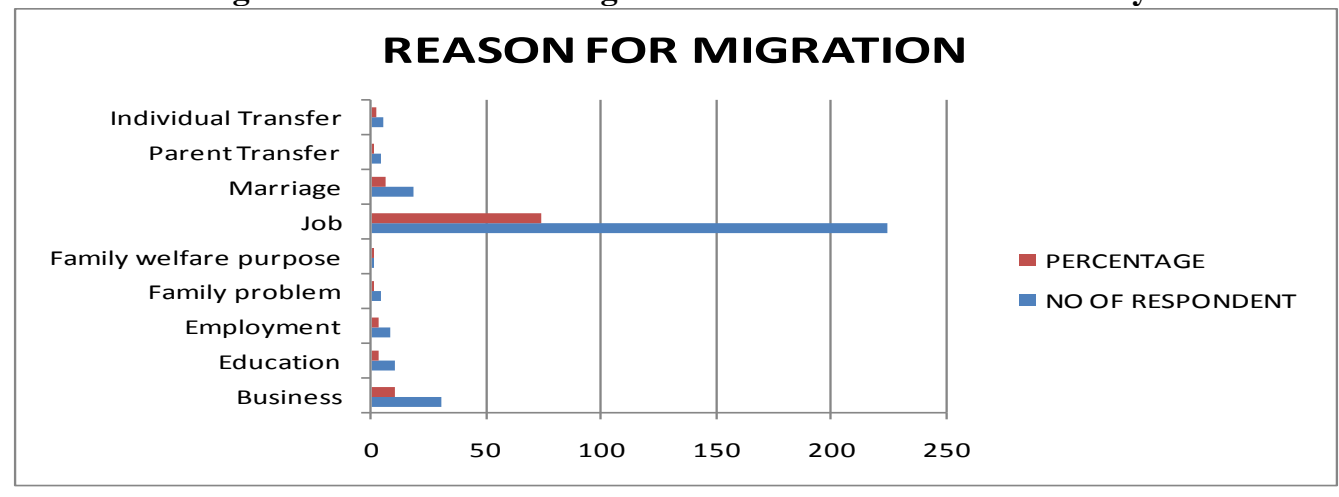




\subsection{Present Residential Zone Of The Migrated People Of Chennai City}

From the Figure - 6 shows that the present residential of the migrated people in Chennai city is taken according to Ten Chennai Corporation zone wise. From this zones Tondiarpet and Pulianthope are 14\% respectively, Basinbridge zone 12\%, Icehouse and Mylapore zone are $11 \%$ respectively, then the Saidapet zone $10 \%$ and all other zones are Nungambakkam 9\%, Kodambakkam 7\%, Ayanavaram and Kilpauk zones are 6\% respectively. Hence, the highest range of migrants occupied in the zones of Tondiarpet and Pulianthope, this has been taken from the migrant people of 305 respondents.

\section{Figure - 6: Present Residenttil Zone Of Migrant People}

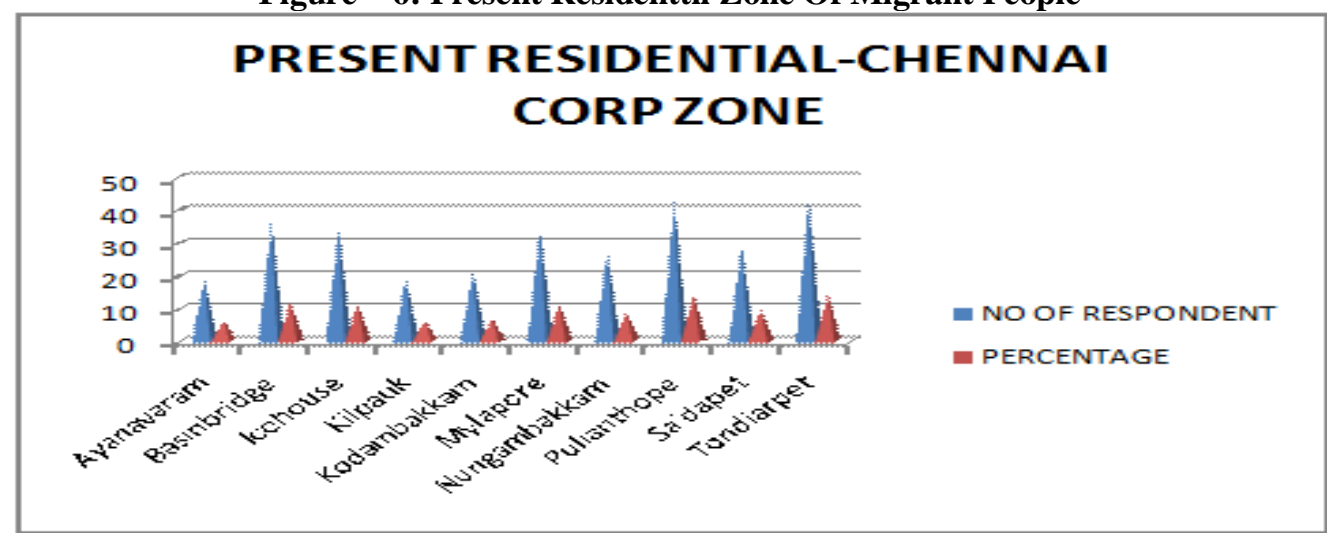

\section{Conclusion}

This study derives that rural to urban migration is a function of push and pull factors that is in rural areas increasing of population did not have job facilities, reasonable income, basic amenities.

The pull factors of better job facilities, good salary, and more income, medical and educational facilities are attracting the rural people to move to the cities like Chennai city. The push factors of no job facilities, low salary, less income, drought, less medical and educational facilities are the push factors of the rural people from rural to urban migration.

Even though, to minimize the rural to urban migration and to prevent to move to cities the following are the some measures has to be taken by government and government organizations.

- To set many more small industries in taluk levels.

- To set big industries, large scale industries in each districts.

- To provide urban facilities in rural areas (PURA).

- To set employment schemes, self employment schemes.

- To provide loans to the skilled, unskilled educated persons.

- To provide better higher secondary schools and higher education facilities.

\section{References:}

[1] Migration in India, hHp://www.india no officer.com/for uns/current-issues/5981-migration- i..18/7/2009.

[2] Mahendra K.Premi, 1987'Pattterns and process of migration”, Allied Publishers Pvt.Ltd.: 1987,Pg.No.258-259 \& Pg.283.

[3] K.Nagaraj, 1987 "Urbanization in Tamilnadu,Karnataka \& Andhra Pradesh, A Comparative prime for 1961-1981 Pg.No.348.

[4] Censes of India 2011

[5] Migration websites.

[6] Data Collections 